\title{
Mesenchymal stem cells in corneal neovascularization: Comparison of different application routes
}

\author{
EMMA GHAZARYAN ${ }^{1,2^{*}}$, YAN ZHANG $^{1 *}$, YUXI HE $^{1}$, XIN LIU ${ }^{1}$, YING LI $^{1}$, JIANAN XIE ${ }^{1}$ and GUANFANG SU ${ }^{1}$ \\ ${ }^{1}$ Department of Ophthalmology, Second Teaching Hospital, Jilin University, Changchun, Jilin 130041, P.R. China; \\ ${ }^{2}$ Eye Laser Center of Shengavit Medical Center, Yerevan State Medical University, Yerevan 0006, Armenia
}

Received February 8, 2016; Accepted June 23, 2016

DOI: $10.3892 / \mathrm{mmr} .2016 .5621$

\begin{abstract}
The purpose of the present study is to investigate the effect of mesenchymal stem cells in corneal neovascularization and wound healing, and to compare the effectiveness of two possible application routes, subconjunctival injection and amniotic membrane transplantation. Chemical injury was induced by application of sodium hydroxide to the rats' corneas. After 7 days, the animals were divided into three groups. Different treatment methods were used for each group as follows: i) Group 1, injection of bone marrow-derived mesenchymal stem cells (BMSCs) under the conjunctiva; ii) group 2, transplantation of amniotic membranes, previously seeded with BMSCs; and iii) group 3, the untreated control group. The eyes were examined using a slit lamp on a weekly basis. After 4 weeks, the animals were sacrificed and corneas were removed for further examination. Corneal flat mounts were made following ink perfusion for improved vessel visualization, image capturing and quantitative evaluation. enzyme-linked immunosorbent assay was performed to detect the levels of vascular endothelial growth factor (VEGF) and matrix metalloproteinase 9 (MMP-9). Reverse transcription-quantitative polymerase chain reaction was used for detection of VEGF-A, MMP-9, Toll-like receptor (TLR)2 and TLR4 gene expression levels. Cryosections were used for histological examination and immunostaining. Statistical analysis (Welch's one-way analysis of variance) demonstrated a significant difference between the groups $[\mathrm{P} \leq 0.05$, confidence interval (CI) 95\%]. The level of injury in group 1 was significantly different from groups 2 and 3. Measurement of the vessel area and VEGF gene expression levels had a similar difference among the groups ( $\mathrm{P} \leq 0.05$, CI 95\%), however
\end{abstract}

Correspondence to: Professor Guanfang $\mathrm{Su}$, Department of Ophthalmology, Second Teaching Hospital, Jilin University, 265 Ziqiang Street, Nanguan, Changchun, Jilin 130041, P.R. China E-mail:sugf2012@163.com

*Contributed equally

Key words: corneal neovascularization, chemical injury, mesenchymal stem cell, amniotic membrane, transplantation the differences for TLR2 and TLR4 were not statistically significant. BMSCs were previously transduced with the green fluorescent protein gene by lentivirus to track the movement of the cells following transplantation. The transplanted cells enhanced corneal wound healing by trophic factor production and immune-regulatory effect, rather than by direct transdifferentiation into corneal cells. The results of the current study demonstrated that BMSCs enhance corneal wound healing and decrease the area of neovascularization. Furthermore, the comparison of two application routes indicated that single subconjunctival injection appeared more effective than transplantation with amniotic membrane.

\section{Introduction}

Approximately ten million people worldwide are bilaterally blind due to corneal involvement $(1,2)$. It is the second most common cause of reversible blindness, following cataracts. The majority of cases are connected with corneal neovascularization $(\mathrm{CNV})$. Various factors can induce $\mathrm{CNV}$, including aniridia, degeneration, inflammation, infection, extended contact lens wear $(3,4)$ and chemical or mechanical injuries $(5,6)$.

Chemical injury of the cornea is an ophthalmic emergency and a common cause of corneal neovascularization and blindness in the developing world. Treatment of the chemical injuries include medical (7) and surgical approaches (8-10). Numerous cases require surgical intervention, particularly limbal stem cell transplantation. This is possible in unilateral disease, when the contralateral cornea is healthy or less damaged. However, there is a risk of limbal stem cell deficiency development in the donor eye. Allogeneic limbal transplantation has been conducted by a number of ophthalmologists, however, results were not satisfactory and treatment requires prolonged immunosuppressive therapy. Other sources of cells, including conjunctival cells (11), buccal mucosal cells, embryonic stem cells (12), induced pluripotent stem cells and mesenchymal stem cells (13-16) have been investigated for reconstruction of the limbal stem cell niche.

Mesenchymal stem cells (MSCs) are a safe therapeutic option and may be used for autologous transplantations. These stem cells were first isolated from bone marrow, but later they were identified in different tissues and organs, including adipose tissue, dental pulp, amniotic fluid and the umbilical 
cord. Previous studies have demonstrated MSCs have plasticity and can differentiate into various cell types $(17,18)$. Furthermore, these cells can regulate immune response by regulation of T cell (19), B cell and NK cell activity (20), and can be safely used for allogeneic transplantation.

MSCs have been used in numerous studies for reconstitution of the corneal surface $(10,14-16,21-30)$. Certain previous studies have demonstrated transdifferentiation ability into corneal cell lines (15,31-34). Often amniotic membranes were used for stem cell expansion and further transplantation into the cornea $(16,23,25,26,30,35)$. However, certain previous studies used supernatants or systemic administration of stem cells. All these techniques are complicated, time-consuming and not accessible in developing countries. Simple subconjunctival injection of stem cells has been proposed by Yao et al (28), which was effective in corneal wound healing.

The aim of the present study was to further investigate the role of MSCs in corneal neovascularization and wound healing, and also to compare the effectiveness of two administration routes, subconjunctival injection and transplantation of amniotic membrane.

\section{Materials and methods}

Animals. Female Wistar rats $(n=48$; age, 6 weeks; weight, 150-180 g) were purchased from the Animal Center of Jilin University (Changchun, China). All animal procedures were handled according to the Association for Research in Vision and Ophthalmology Statements for the Use of Animals in Ophthalmic and Vision Research and were approved by Jilin University Animal Care and Use Committee.

The animals were housed 2 per cage at a temperature of $24-26^{\circ} \mathrm{C}$, humidity $55-60 \%$ and a $12 \mathrm{~h}$ light/dark cycle, with ad libitum access to food and water. The rats were anesthetized by injection of $10 \%$ chloral hydrate $(4 \mathrm{ml} / \mathrm{kg})$. At the end of the study (week 5), animals were sacrificed using an overdose of the anesthetic $(10 \mathrm{ml} / \mathrm{kg})$.

Isolation, culture and characterization of BMSCs. BMSCs were isolated and cultured according to the previously described protocols (36). Briefly, the marrow cavity was flushed with $1 \mathrm{ml}$ Dulbecco's modified Eagle's medium (DMEM)/F12 (Gibco; Thermo Fisher Scientific, Inc., Waltham, MA, USA). The medium with the bone marrow was transferred into $2 \mathrm{ml}$ Eppendorf tubes and centrifuged at $350 \mathrm{x}$ g for $5 \mathrm{~min}$ at room temperature. The supernatant was discarded and $2 \mathrm{ml}$ fresh DMEM/F12 and 10\% fetal bovine serum (FBS; Gibco; Thermo Fisher Scientific, Inc.), without antibiotics, was added to the tube. The suspension was transferred into $25 \mathrm{ml}$ cell culture flasks and incubated at $37^{\circ} \mathrm{C}$ in a $5 \% \mathrm{CO}_{2}$ incubator. After $48 \mathrm{~h}$, the medium was discarded, with the non-adherent cells, and $3 \mathrm{ml}$ fresh culture medium was added to the flask. The medium was changed once every 3 days, until cells reached $80-90 \%$ confluence. Expression of cluster of differentiation (CD)90, CD45, CD11b and CD44 was detected by flow cytometry. Briefly, passage 3 cells were trypsinized, centrifuged at $60 \mathrm{x} g$ for $5 \mathrm{~min}$ at room temperature and were washed with three times with phosphate-buffered saline (PBS). Diluted monoclonal mouse anti-CD11b (cat. no. CBL1512 CB11; 1:200; EMD Millipore, Billerica, MA, USA) and monoclonal mouse
anti-CD44 (eBioscience, Inc., San Diego, USA) were added to the cells and incubated at $4^{\circ} \mathrm{C}$ for $1 \mathrm{~h}$. PBS was added to the control group. After $1 \mathrm{~h}$, the cells were washed with three times PBS for $5 \mathrm{~min}$. Fluorescein isothiocyanate-conjugated goat anti-rabbit secondary antibody (cat. no. 31635; 1:200; Thermo Fisher Scientific, Inc.) was added to the cells and incubated at $4^{\circ} \mathrm{C}$ for $30 \mathrm{~min}$. The cells were washed 3 times with PBS prior to detection by Epics XL flow cytometer (Beckman Coulter, Inc., Brea, CA, USA).

For CD90 and CD45 direct labeling was conducted with diluted monoclonal mouse anti-CD90(cat. no. 554897; 1:200; BD Biosciences, Franklin Lakes, NJ, USA) and monoclonal mouse anti-CD45 antibodies (cat. no. 11-0461; 1:50; eBioscience, Inc.) to washed cell suspension, which was incubated at $4^{\circ} \mathrm{C}$ for $60 \mathrm{~min}$, washed with PBS and detected by flow cytometer.

Transduction of BMSCs with lentivirus. BMSCs from passage 2 were transduced with the green fluorescent protein (GFP) gene using a lentivirus system (ViraPower ${ }^{\mathrm{TM}}$ Lentiviral Packaging mix; Invitrogen; Thermo Fisher Scientific, Inc.) in order to follow the movement of transplanted cells.

Optimal multiplicity of infection (MOI) was determined in preliminary experiments. The toxicity and transduction efficacy was compared among MOI 1, 5, 10, 50 and 100, an MOI of 10 was demonstrated to be optimal. To conduct the transduction, BMSCs from passage 2 were added to 24 well plate $\left(1 \times 10^{5}\right.$ cells/well) with $500 \mu \mathrm{l}$ DMEM/F12 and $10 \% \mathrm{FBS}$, and incubated at $37^{\circ} \mathrm{C}$ in $5 \% \mathrm{CO}_{2}$ overnight. Subsequently, diluted virus was added into the wells with $5 \mu \mathrm{l} / \mathrm{ml}$ Polybrene (Invitrogen; Thermo Fisher Scientific, Inc.) with $100 \mu 1$ DMEM/F12 and 10\% FBS and the cells were incubated overnight. After $24 \mathrm{~h}$, the medium was changed and on day 4 , $10 \mathrm{ng} / \mathrm{ml}$ puromycin (Invitrogen; Thermo Fisher Scientific, Inc.) was added to each well to produce a homogenous generation of transduced cells. On the following day the medium was changed again and on day 6 the transduction effect was observed using inverted fluorescence microscopy (Olympus Corporation, Tokyo, Japan). Second generation transduced cells were used in the following experiments.

Culture of BMSCs on denuded amniotic membrane. Following obtaining informed consent, human amniotic membranes (HAM) were obtained from healthy pregnant women during their planned caesarean sections. Under sterile conditions, the chorion was manually separated from the amniotic membrane and all remaining blood and chorionic membrane pieces were removed. The HAM was cut into $2 \times 2 \mathrm{~mm}^{2}$ pieces and trypsin/EDTA (Sigma-Aldrich, St. Louis, MO, USA) was added to each piece and incubated at $37^{\circ} \mathrm{C}$ in $5 \% \mathrm{CO}_{2}$ for $30 \mathrm{~min}$. The detached epithelial layer was removed using a cell scrubber in a gentle manner. The pieces were stained with 4',6-diamidino-2-phenylindole (DAPI; Sigma-Aldrich, St. Louis, MO, USA) and examined by confocal microscopy (Olympus Corporation).

Following confirmation that the HAMs were fully denuded, second generation transduced BMSCs were seeded onto the membranes $\left(1 \times 10^{5}\right.$ cells/piece). The air-lifting culture technique was used with little culture medium. After 4 days, cells reached confluence and DAPI was used to visualize the nuclei 
of the cells grown on the denuded (d)-HAM, and examination was conducted under confocal laser scanning microscopy. Following confirmation of positive results, the membranes seeded with BMSCs were used for transplantation.

Preparation of animal models and transplantation. All animal experiments were handled according to the animal protocols approved by Jilin University Animal Care and Use Committee. The Wistar rats were anesthetized by injection of $10 \%$ chloral hydrate $(4 \mathrm{ml} / \mathrm{kg})$ and anesthetic eye drops were applied for topical anesthesia. Circular discs (diameter, $3 \mathrm{~mm}$ ) from filter paper were soaked in $0.4 \mathrm{ml} 1 \mathrm{~mol} / \mathrm{l}$ sodium hydroxide solution (Beijing Dingguo Changsheng Biotechnology Co., Ltd., Beijing, China). The disc was applied to the center of the cornea of the right eye for $30 \mathrm{sec}$, following removal of the disc, the surface of the eye was thoroughly washed by $60 \mathrm{ml}$ normal saline for $1 \mathrm{~min}$. The eyes were examined daily by penlight. The criteria presented in Table II were used for classification of the severity of injury. After 7 days, the rats were anesthetized and the eyes were examined under a slit-lamp microscope following the addition of fluorescein dye using Oftan Flurekain eye drops (Santen Oy, Tampere, Finland). Preliminary data were recorded and the rats received transplantation. The rats used in the present study $(n=48)$ were divided into 3 groups as follows: i) Group $1(n=16)$ received subconjunctival injection of BMSCs suspended in PBS; ii) group $2(n=16)$ received amniotic membrane transplantation seeded with BMSCs; and iii) group $3(n=16)$ received no treatment and served as the control group.

Cells from the second generation of lentiviral-transduced BMSCs $\left(1 \times 10^{6}\right)$ were centrifuged and washed with PBS three times and resuspended in $0.1 \mathrm{ml}$ PBS. Anesthetized rats from group 1 received subconjunctival injection of $0.1 \mathrm{ml}$ PBS containing cells by $1 \mathrm{ml}$ insulin syringe under a ophthalmic surgical microscope. The pieces of d-HAM seeded with BMSCs were divided into 4 pieces $\left(1 \times 1 \mathrm{~mm}^{2}\right)$ and anesthetized rats from group 2 received d-HAM transplantation. Following application of topical anesthetic, the amniotic membrane was placed on the cornea and sutured by six interrupted 10.0 nylon sutures with the epithelial side facing up. Thereafter, eyelids were sutured together by 6.0 nylon sutures. The rats were examined daily with pen light and weekly with a slit-lamp for 4 weeks. Eyelids were opened after 5 days, and the majority of the amniotic membranes were absorbed. After 4 weeks, the animals were sacrificed by chloral hydrate overdose and the corneas were excised for use in the experiments.

Preparation of corneal flat mounts following ink perfusion. This step used five rats from each group. Following anesthesia, the thoracic cavity was opened and thoracic aorta was separated from the surrounding tissue using dissecting scissors to avoid wall disruption. The thoracic aorta was ligated. An intravenous cannula (or catheter) was inserted into the aorta above the ligated site. The right atrium was cut to allow blood outflow and $60 \mathrm{ml}$ normal saline was used to clear the vessels of blood. When the fluid from the atrium was cleared, 10-20 ml ink was injected. The injection was stopped when the eyes, ears and upper limbs of the rat were observed to be staining dark black. The catheter was then removed and the eyeballs were enucleated and post-fixed in $4 \%$ paraformaldehyde for
$3 \mathrm{~h}$. The corneas were incised, flattened by four incisions and mounted on glass slides. Images of the slides were captured by a camera attached to the light microscope (Olympus Corporation) and analyzed using Image-Pro Plus 6.0 software (Media Cybernetics, Inc., Rockville, MD, USA).

Cryosections. Cryosectioning was conducted with three eyes from each group. Fresh, enucleated unfixed eyes were frozen in optimal cutting temperature compound (Sakura Finetek USA, Inc., Torrance, CA, USA) on a tissue mold in the cryostat (Leica Microsystems GmbH, Wetzlar, Germany). Sections were cut at $8-\mu \mathrm{m}$ at $-20^{\circ} \mathrm{C}$ in cryostat and divided into three groups, sections were fixed and dehydrated and stained with hematoxylin and eosin, immediately examined under fluorescent microscope for labeled BMSC detection without fixation or dehydration, or used for immunochemical analyzes to detect vascular endothelial growth factor (VEGF) and matrix metalloproteinase 9 (MMP-9) levels.

Enzyme-linked immunosorbent assay (ELISA). VEGF protein level was detected using an Rat VEGF Quantikine ELISA kit (R\&D Systems, Inc., Minneapolis, MN, USA). From each group 4 corneas were excised, cut into small pieces and homogenized using a glass mortar. Subsequently, $400 \mu 1$ radioimmunoprecipitation assay buffer containing $1 \%$ PMSF (Sigma-Aldrich) was added to the pieces and incubated for $30 \mathrm{~min}$ on the ice. The mixture was treated with an ultrasonic homogenizer, centrifuged at $350 \mathrm{x}$ g for $5 \mathrm{~min}$ at $4^{\circ} \mathrm{C}$, and the supernatant was collected for further procedures. The ELISA was performed according to the manufacturer's protocol.

Reverse transcription-quantitative polymerase chain reaction $(R T-q P C R)$. Total RNA was extracted from four eyes from each group using an RNAiso Plus kit (Takara Biotechnology Co., Ltd., Dalian, China) according to the manufacturer's protocol. The mRNA integrity was confirmed by $1.5 \%$ agarose gel electrophoresis.

Following extraction of the mRNA, reverse transcription was performed to synthesize cDNA according to the manufacturer's protocol using One Step SYBR PrimeScript Plus RT-PCR kit (Takara Biotechnology Co., Ltd.). PCR was conducted using SYBR Green and designed primers from Sangon Biotech (Table I). Each reaction required $1 \mu \mathrm{l}$ of the previously synthesized cDNA, which was mixed with SGExcelFastSYBR mix, containing ROX (Sangon Company, Shanghai, China), forward and reverse primers, and RNase-free water. The qPCR was performed in a LightCycler 480 II (Roche Diagnostics, Basel, Switzerland) using the following program: $72^{\circ} \mathrm{C}$ for $5 \mathrm{~min} ; 94^{\circ} \mathrm{C}$ for $3 \mathrm{~min}$, stage $3: 94^{\circ} \mathrm{C}$ for $20 \mathrm{sec}, 57^{\circ} \mathrm{C}$ for $20 \mathrm{sec}$ and $72^{\circ} \mathrm{C}$ for $20 \mathrm{sec}$ for $40 \mathrm{cycles}$ and $72^{\circ} \mathrm{C}$ for $3 \mathrm{~min}$. Analysis was performed with LightCycler software, version 1.5.0, which allowed precise analysis of data. Each sample was examined in triplicate.

Statistical analysis. Clinical results were calculated using Welch's analysis of variance test with Dunnett's T3 post-hoc test. Mean values and standard deviations were calculated for vessel length and the Kruskal-Wallis non-parametric test was used to compare mean values of the three groups. Nonparametric median test was used to compare qPCR and ELISA test results in three groups. All analyses were conducted using SPSS 22.0 
(IBM SPSS, Armonk, NY, USA) $\mathrm{P} \leq 0.05$ was considered to indicate a statistically significant difference.

\section{Results}

BMSCs were isolated and characterized. After $48 \mathrm{~h}$ isolation, the cells were washed with PBS and non-adherent cells were washed out of the flasks. A number of small colonies of adherent cells were scattered across the bottom of the flasks. After 2-3 days, the cells began to grow and elongate, becoming a spindle shape similar to fibroblasts. Following 2-3 subcultures, cells had typical phenotypic characteristics of BMSCs, they were attached to the bottom of the flask with a spindle-like shape and self-renewal ability (Fig. 1A).

The flow cytometry results demonstrated that $95 \%$ of the cells were positive for CD90 expression, $75 \%$ were positive for CD44 expression, and expression of CD11b and CD45 were positive in only in 0.5 and $0.2 \%$ of cells, respectively (Fig. 1B). This pattern of surface marker expression is consistent with previous descriptions of BMSCs $(17,18,20)$.

Cell transduction with lentivirus was successful. After 6 days, transduction cultures were examined under fluorescence microscopy. Detection of GFP provided evidence of successful transduction and efficacy was $\sim 50-60 \%$. At MOI 10, the virus did not result in toxicity and did not affect the self-renewal ability of the cells (Fig. 1C).

BMSCs were cultured on denuded amniotic membrane. The epithelial layer of the amniotic membrane was removed by enzymatic and mechanical processes. The membranes were stained with DAPI and examined under a confocal laser scanning microscope. Examination indicated that all epithelial cells were effectively removed from the membranes as no DAPI stained cells were observed on the surface of the d-HAM.

Seeded BMSCs exhibited exponential growth on d-HAM and reached confluence within 4 days. Confocal microscopy was used to detect mesenchymal stem cells expressing GFP on the amniotic membranes (Fig. 2).

The rat model was successfully produced with no significant difference in level of injury. A total 48 rats were used in the present study. Slit-lamp examination was conducted on the day of injury and then weekly until week 5 (Fig. 3). Examination on day 1 demonstrated a total epithelial defect at the applied disc area, which stained with fluorescein dye. After 7 days the areas were again stained with the dye in all rats.

Three key characteristics were measured, corneal opacity, area of the neovascularization, and area of the epithelial defect stained with fluorescein. A four scale grading system was used to classify the severity of injury (Table II).

The animals were randomly divided into three groups. Statistical analysis was conducted on data from all the groups to compare the level of injury in each group. The result demonstrated there was no statistically significant difference between groups $[\mathrm{P}=0.11$, confidence limit $(\mathrm{CL}) 95 \%]$ with all animals developing middle to severe level injury. Following treatment, the corneas were examined daily with pen light and weekly with slit-lamp for 4 weeks. At week 4 , none of the animals exhibited any adverse reaction to the treatments. Following the final results were obtained in week 4, the animals were sacrificed. Statistical analysis indicated a statistically significant difference in severity within the 3 groups $\left[\mathrm{P}=1.9 \times 10^{-5}\right.$, confidence interval (CI) 95\%] and post-hoc tests indicated that the differences were between group 1 with group $2(\mathrm{P}=0.00016$, CI 95\%), and group 1 and group 3 ( $\mathrm{P}=0.00037$, CI 95\%) were also statistically significant. Thus, a single subconjunctival injection of BMSCs had greater impact on corneal wound healing, than BMSCs on amniotic membrane transplantation (Fig. 3).

Length of the vessel, level of VEGF and gene expression of VEGF, MMP-9, Toll-like receptor (TLR)2 and TLR4 were different among the three groups. Ink perfusion was used for improved visualization of new vessels. In total, images of 15 flat mounts were captured by a digital camera attached to a light microscope. The images were processed with Image-Pro Plus 6.0 computer software. Area of neovascularization and total length for each sample was calculated and used for statistical analysis. The results demonstrated that the mean length of the vessels was significantly different among the 3 groups $\left(\chi^{2}=10.50, \mathrm{P}=0.005, \mathrm{CL} 95 \%\right)$. The level of VEGF protein and gene expression also demonstrated similar differences (Fig. 4). The difference among the 3 groups was significant with $\mathrm{P}=0.02, \mathrm{CI} 95 \%$ and according to the post-hoc tests difference was observed between groups 1 and 2 and groups 1 and 3 .

VEGF expression significantly decreased following treatment. Results were determined relative to the reference gene, actin, and the level of expression of VEGF was demonstrated to be statistically significant between group 1 and group 2, and group 1 and group 3 ( $\mathrm{P}=0.03$, CI 95\%; Fig. 4F). The expression of MMP-9 was significantly decreased within the 3 groups, and a difference was observed within group 1 and $2(\mathrm{P}=0.004$, CI 95\%) and group 1 and 3 ( $P=0.001$, CI 95\%; Fig. 4G). No difference in TLR2 and TLR4 gene expression was observed between the 3 groups ( $\mathrm{P}=0.06$, CI 95\%; Fig. $4 \mathrm{H}$ and I).

Histopathology and immunochemistry. Cryosections stained with hematoxylin and eosin demonstrated that the corneas from the group 1 were thinner, the stromas were compact with reduced infiltration of inflammatory cells, and the epithelial layers were fully recovered (Fig. 5). In groups 2 and 3, new vessels were marked in the sections from the central area of the cornea, which were absent in group 1.

To be able to track the movement and localization of the cells, GFP was expressed in the cells. Fresh, non-fixed cryosections were immediately examined under a confocal laser scanning microscope. GFP-positive cells were not detected in the cornea. Thus, the present study suggests stem cells did not migrate into the cornea or transdifferentiate into limbal or corneal cell lines.

\section{Discussion}

Corneal blindness has a large impact on society. However, unlike retinal degeneration and glaucoma, it is reversible and the majority of cases of corneal blindness are treatable and preventable. 
Table I. Sequences of the primers.

Primer (5' to $\left.3^{\prime}\right)$

\begin{tabular}{llc}
\cline { 2 - 3 } Gene & \multicolumn{1}{c}{ Forward } & Reverse \\
\hline VEGF & CTTGAGTTGGGAGGAGGATG & TGGCAGGCAAACAGACTTC \\
MMP-9 & ACCCTGCGTATTTCCATTCA & ATCTCTCCTGCCGAGTTGC \\
TLR-2 & AAACTGTGTTCGTGCTTTCTG & GCGTCATTGTTCTCGTCAAA \\
TLR-4 & TGGCATCATCTTCATTGTCC & CAGAGCATTGTCCTCCCACT \\
-actin & GCTACAGCTTCACCACCACA & ATCGTACTCCTGCTTGCTGA
\end{tabular}

VEGF, vascular endothelial growth factor; MMP-9, matrix metalloproteinase 9; TLR, Toll-like receptor.

Table II. Evaluation score for the corneal chemical injury.

\begin{tabular}{|c|c|c|c|c|c|}
\hline Score & 0 & 1 & 2 & 3 & 4 \\
\hline $\begin{array}{l}\text { Corneal } \\
\text { opacity }\end{array}$ & $\begin{array}{l}\text { No opacity, } \\
\text { transparent } \\
\text { cornea }\end{array}$ & $\begin{array}{l}\text { Slight opacity, } \\
\text { visible pupil } \\
\text { and iris } \\
\text { texture }\end{array}$ & $\begin{array}{l}\text { Moderate opacity, } \\
\text { iris texture is } \\
\text { unclear, but } \\
\text { pupillary margin } \\
\text { is visible }\end{array}$ & $\begin{array}{l}\text { Severe opacity, } \\
\text { pupillary } \\
\text { margin is } \\
\text { visible } \\
\text { vaguely }\end{array}$ & $\begin{array}{l}\text { Very severe opacity, } \\
\text { nothing can be } \\
\text { visualized under } \\
\text { cornea }\end{array}$ \\
\hline $\begin{array}{l}\text { Epithelial } \\
\text { defect }\end{array}$ & No defect & $\begin{array}{l}\leq 1 / 4 \text { of the } \\
\text { corneal surface }\end{array}$ & $\begin{array}{l}1 / 4-1 / 2 \text { of the } \\
\text { corneal surface }\end{array}$ & $\begin{array}{l}1 / 2-3 / 4 \text { of the } \\
\text { corneal surface }\end{array}$ & $\begin{array}{l}\geq 3 / 4 \text { of } \\
\text { the corneal surface }\end{array}$ \\
\hline $\begin{array}{l}\text { Neovascu- } \\
\text { larization }\end{array}$ & No vessel & $\begin{array}{l}2 \text { mm within } \\
\text { limbus }\end{array}$ & $\begin{array}{l}\leq 1 / 2 \text { of the } \\
\text { corneal surface }\end{array}$ & $\begin{array}{l}\geq 1 / 2 \text { of the } \\
\text { corneal surface }\end{array}$ & $\begin{array}{l}\text { Total surface of } \\
\text { the corneal surface }\end{array}$ \\
\hline
\end{tabular}

A

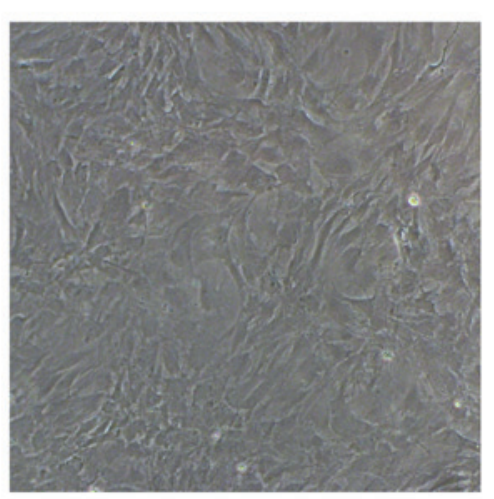

B

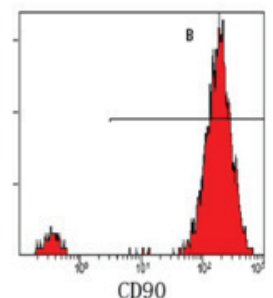

CD90

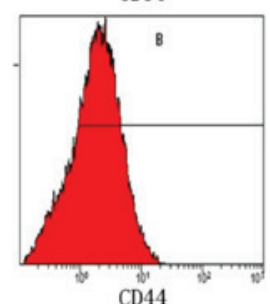

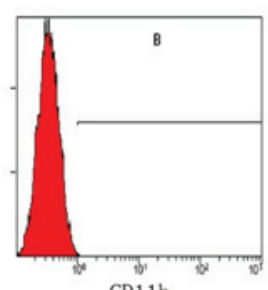

$\mathrm{CD} 11 \mathrm{~b}$

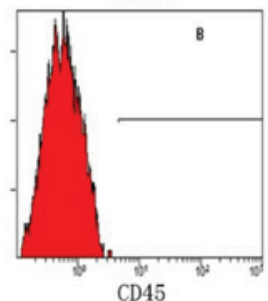

C

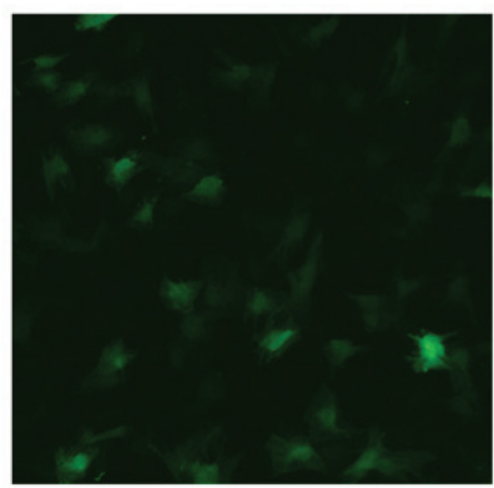

Figure 1. Bone marrow-derived mesenchymal stem cells under fluorescence microscopy (magnification, x20). (A) Cells are attached to the bottom of the culture dish exhibit a spindle shape. (B) Flow cytometry results, cells express CD90 and CD44 and are negative for CD45 and CD11b. (C) Green fluorescent protein positive cells are observable under fluorescence microscopy. CD, cluster of differentiation.

A number triggers affect the cornea and result in corneal neovascularization, including infection, degeneration, and injury. People in developing countries are more susceptible to these triggers, however, extended contact lens wear is also a risk factor.

The majority of CNV cases require surgical intervention and transplantation is a common therapeutic strategy. These transplantation of a whole cornea or its layers, amniotic membranes, conjunctiva, cultured oral mucosal epithelial cell sheets and limbal stem cells. Transplantation of the whole cornea or certain parts is a common treatment method worldwide. It has $95 \%$ success rate, however, for patients with already neovascularized corneal beds, the success rate decreases to $50 \%$. In addition, there is a shortage of donor corneal tissues in the majority of countries, making corneal transplantation an expensive and difficult method, in addition to the requirement 

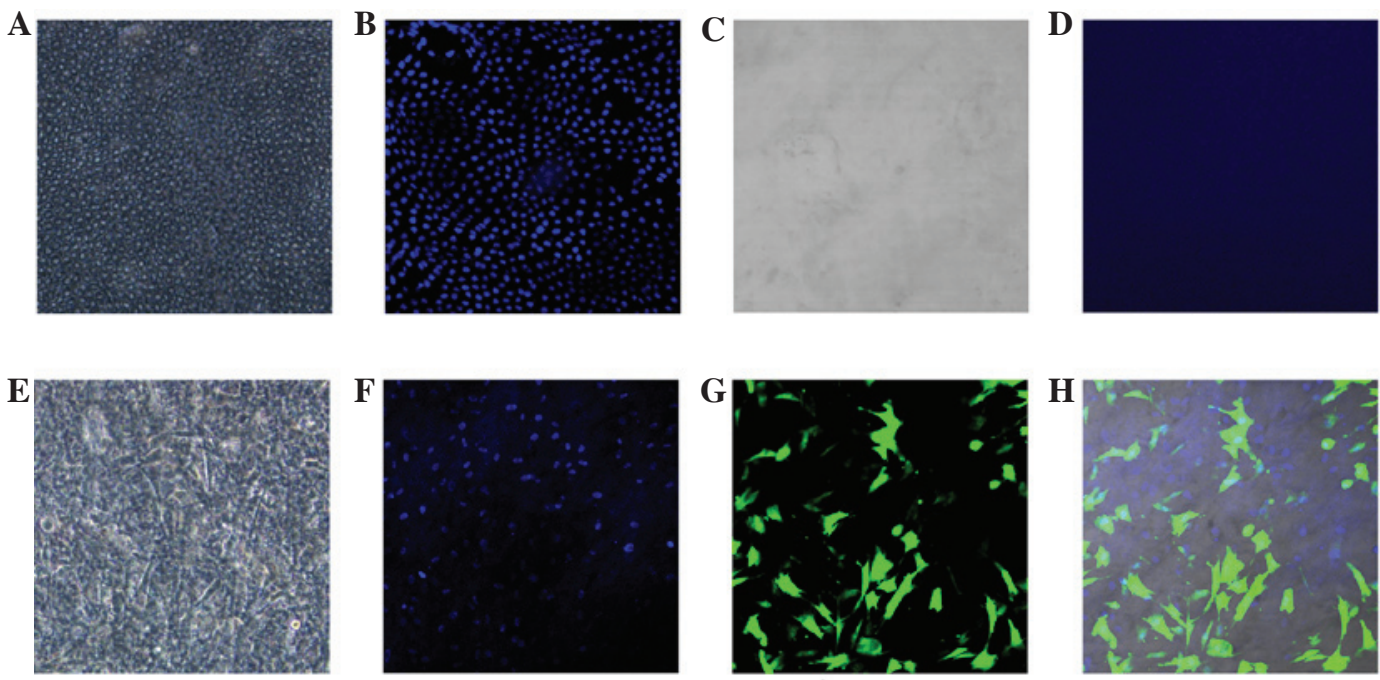

Figure 2. Amniotic membrane with cultured stem cells under confocal microscope (magnification, $\mathrm{x} 40$ ). (A) Normal amniotic membrane with epithelial layer, (B) epithelial cell nuclei stained with DAPI demonstrated regular arrangement; (C) denuded amniotic membrane with (D) no visible DAPI stained nuclei; (E) amniotic membrane with cultured stem cells; (F) nuclei of stem cells stained with DAPI demonstrated a irregular arrangement; (G) stem cells expressing GFP protein; (H) GFP-positive cells with DAPI stained nuclei. DAPI, 4',6-diamidino-2-phenylindole; GFP, green fluorescent protein.

A

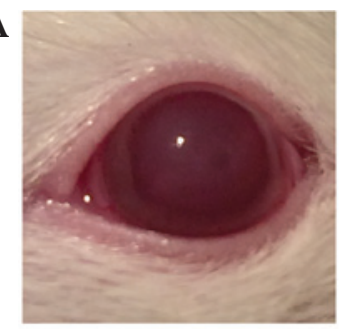

B

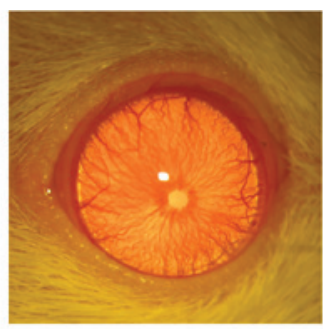

$\mathbf{E}$

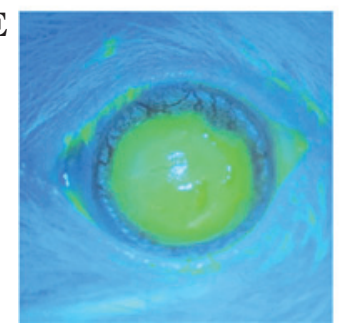

$\mathbf{F}$

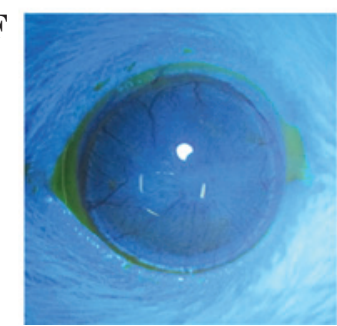

C

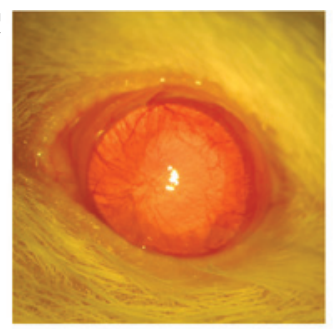

G

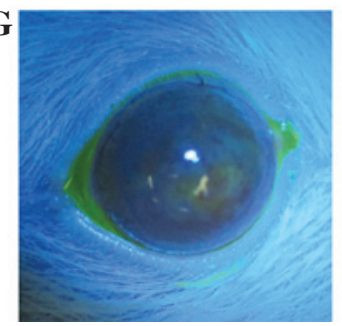

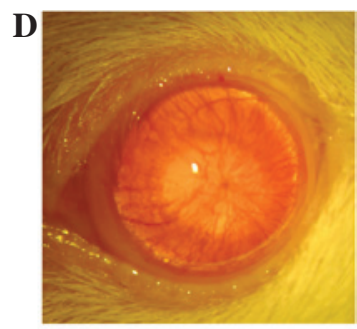

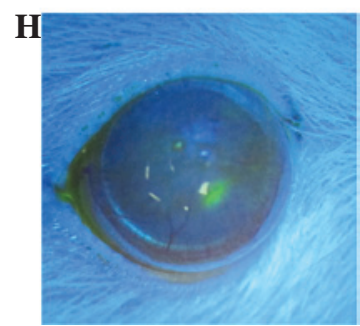

Figure 3. Corneal surface evaluation prior to and 4 weeks after treatments. (A-H) Images of rat corneas. (A) Cornea on the day of injury, (E) total epithelial defect stained with fluorescein dye; (B and F) Group 1, clear, smooth cornea without epithelial defects or vessels following 4 weeks of subconjunctival injection; (C and G) Group 2, cornea with irregular surface and new vessels 4 weeks following amniotic membrane transplantation; (D and H) Group 3 (control), small epithelial defect stained with fluorescein dye and new vessels visible.

for immunosuppression. Thus, medical specialists are aiming to develop novel treatment methods, which can be effective and safe for a greater number of patients. Mesenchymal stem cells are a promising source of cells for transplantation, as they do not raise ethical issues, have low tumorigenesis potential, and they can be used for autologous and allogeneic transplantation. Transplantation of mesenchymal stem cells is also a good option for treatment of corneal injuries. Previous studies have reported the beneficial effect of MSCs in corneal wound healing and neovascularization $(24,26,28-30)$. The majority of the cases used HAM as a bio-scaffold for culture and transplantation of stem cells. However, this technique can be complicated, while subconjunctival injection is a simple technique used in ophthalmic clinics on a daily basis. Thus, direct injection of stem cells under the conjunctiva near the limbus may be a simple and safe method of cell transplantation. Yao et al (28) confirmed that simple subconjunctival injection enhanced corneal wound healing and decreased neovascularization. This procedure can be repeated a number of times. Thus, the present study aimed to investigate this treatment option and to compare the effectiveness and feasibility of two possible application routes, direct subconjunctival injection of stem cells and transplantation on d-HAM. To the best of our knowledge, this is the first paper to discuss the comparison of these two main routes.

The results of the present study demonstrated that mesenchymal stem cells enhance corneal wound healing and decrease neovascularization ( $\mathrm{P}=1.9 \times 10^{-5}$, CI 95\%). Notably, the comparison of two application routes demonstrated that the subconjunctival injection is more effective than 
$\mathbf{A}$
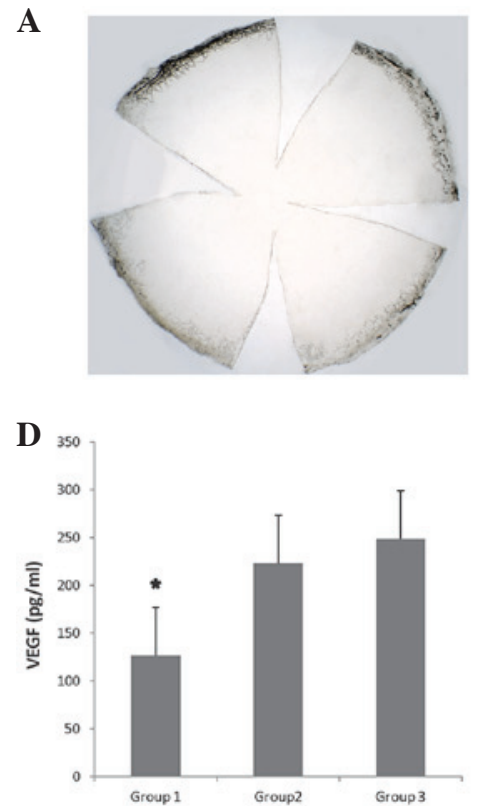

G

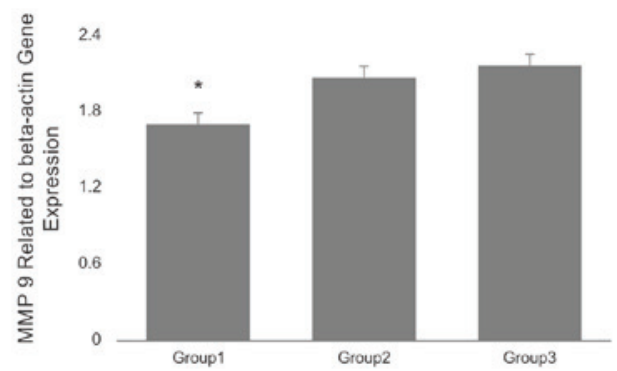

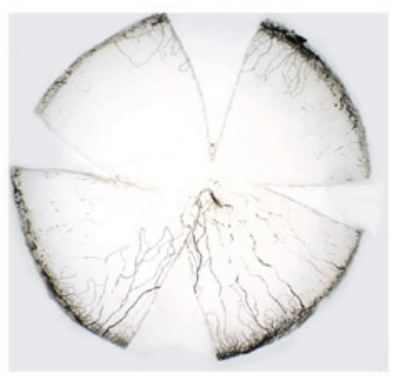

C
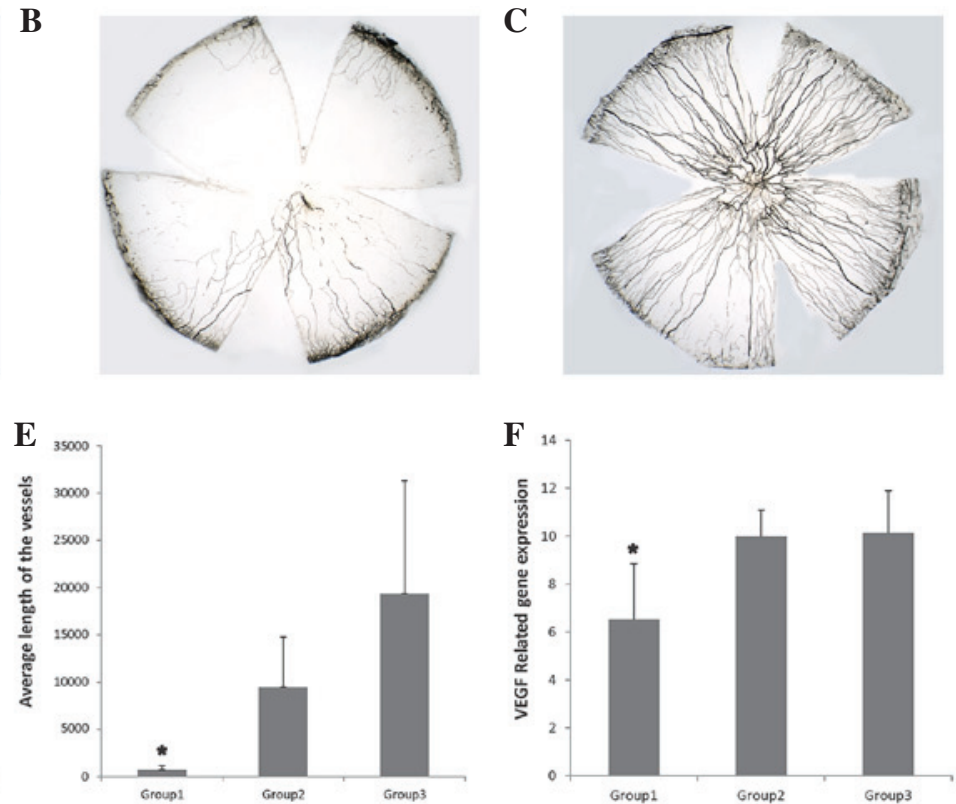

H

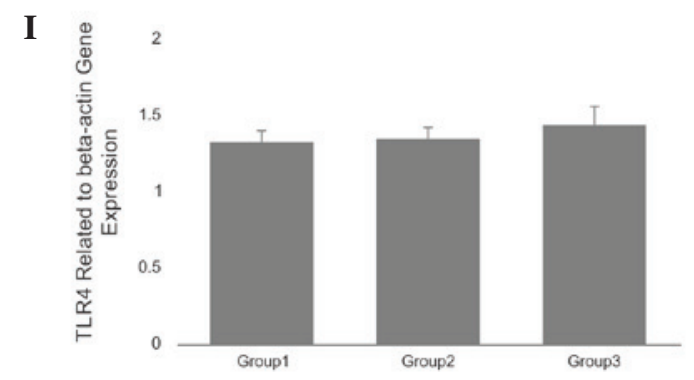

Figure 4. Corneal flat mounts under light microscope (magnification, x10). (A) Subconjunctival injection group (group 1), vessels are short and only in one quadrant; (B) amniotic membrane transplantation group (group 2), vessels are in more than half of the cornea and reach to the center; (C) control group (group 3), vessels are over the entire cornea; (D) VEGF protein level detected by ELISA; (E) length of the vessels measured by Image-Pro Plus 6.0; (F) VEGF, (G) MMP-9, (H) TLR2 and (I) TLR4 gene expression relative to actin. ${ }^{*} \mathrm{P} \leq 0.05,95 \%$ confidence interval. VEGF, vascular endothelial growth factor.

A

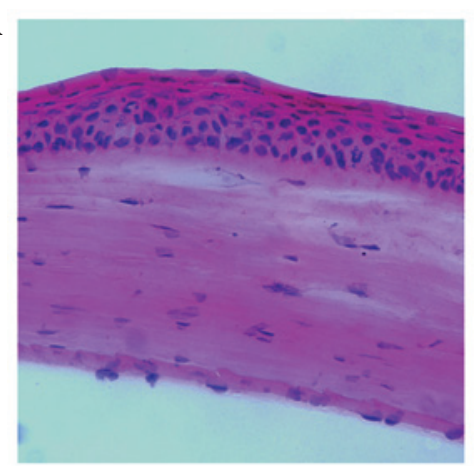

B

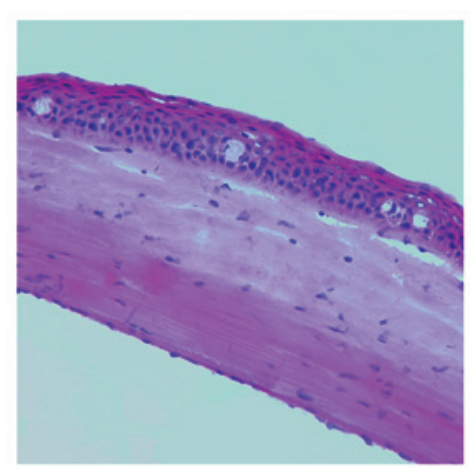

C

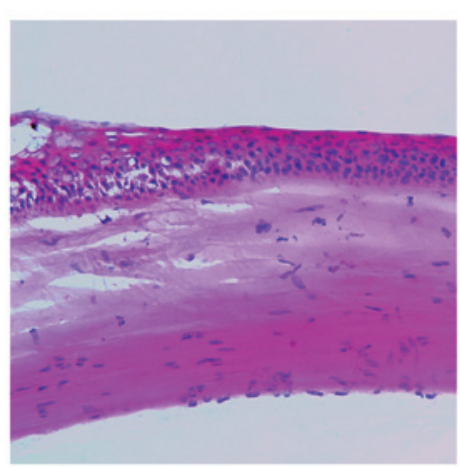

Figure 5. Cryosections stained with hematoxylin and eosin under phase-contrast microscopy (magnification, x20). (A) Group 1, epithelium is fully recovered and the stroma is compact; (B) group 2, epithelium is recovered, however, new vessels are observed and stroma is swollen; (C) group 3, epithelium is not fully recovered and severe stromal edema is observed. 
transplantation with the amniotic membrane $(\mathrm{P}=0.00016, \mathrm{CI}$ $95 \%$ ). This may be due to the short survival time of amniotic membranes on the injured corneas. The difference in clinical outcome was predominantly significant for neovascularization, rather than for epithelial defect or opacity. The expression of VEGF was reduced in the treatment groups, particularly in the subconjunctival injection group.

VEGF and MMP-9 gene expression was reduced in the treatment groups compared with the control group. The gene expression levels of TLR2 and TLR4 were close to equal in the 3 groups. Due to the absence of previous studies on these markers, the present study may have observed this outcome as a result of the prolonged observation period. TLR2 and TLR4 are components of innate immune system and are involved in the initiation of the inflammatory process. Thus, TLR2 and TLR4 had returned to their normal level of expression following 5 weeks.

In order to track the movement of the transplanted cells, they were transduced with the GFP gene using lentiviral vectors. Following transplantation (after 4 weeks) no GFP-positive cells were observed in the corneal sections. Thus, the present study hypothesizes that the underlying mechanism of action was trophic factor production and regulation of the inflammatory process and angiogenesis. Histopathology indicated reduced infiltration of inflammatory cells and neovascularization in the treatment groups, compared with the control.

None of the animals in the present study exhibited an adverse reaction to the treatment. Transplantation of allogeneic cells was successful without episodes of immune rejection.

Corneal blindness is the second leading cause of blindness worldwide and is an important health burden. A number of treatment methods have been implemented in ophthalmic clinics for treatment of $\mathrm{CNV}$, however, for certain patients none of the current options are acceptable. The majority of modern therapeutic strategies are expensive and require specific equipment and skilled professionals. Developing countries, in particular, have a shortage of those and a high rate of corneal involvement. The development of inexpensive, feasible and effective treatment methods in these areas are key. Subconjunctival injection is a simple technique routinely used in eye centers around the world. Mesenchymal stem cells can be easily obtained from 'medical wastes', including ex placenta and amniotic fluid after delivery, adipose tissue after liposuction and be safely used in autologous and allogeneic transplantations. They have been used in various animal studies and numerous clinical trials. All reports on their safety issues have been satisfactory.

In conclusion, the present study demonstrated that single subconjunctival injection of stem cells is more effective, than their transplantation using amniotic membranes. This method requires further investigation and there are two currently running clinical trials using mesenchymal stem cells in corneal disease. However, further clinical trials must be conducted prior to gaining approval for use in clinical practice. This method may fulfill requirements for an effective treatment and has potential to be in clinical use in the near future.

\section{Acknowledgements}

The present study was supported by the NSFC Fund, and Science and Technology Department (grant no. 20130413025GH) and
Health Department of Jilin Province (grant no. 2013Q005) funds.

\section{References}

1. Robaei D and Watson S: Corneal blindness: A global problem Clin Experiment Ophthalmol 42: 213-214, 2014.

2. Whitcher JP, Srinivasan M and Upadhyay MP: Corneal blindness: A global perspective. Bull World Health Organ 79: 214-221, 2001.

3. Alvord LA, Hall WJ, Keyes LD, Morgan CF and Winterton LC: Corneal oxygen distribution with contact lens wear. Cornea 26: 654-664, 2007

4. Martins TG, Costa AL, Alves MR and Gonçalves MM: Contact lens use with intraestromal hemorrhage secondary to corneal neovascularization. Einstein (Sao Paulo) 10: 524-525, 2012 (In English, Portuguese).

5. Cursiefen C, Küchle M and Naumann GO: Angiogenesis in corneal diseases: Histopathologic evaluation of 254 human corneal buttons with neovascularization. Cornea 17: 611-613, 1998.

6. Giacomini C, Ferrari G, Bignami F and Rama P: Alkali burn versus suture-induced corneal neovascularization in C57BL/6 mice: An overview of two common animal models of corneal neovascularization. Exp Eye Res 121: 1-4, 2014.

7. Hsu CC, Chang HM, Lin TC, Hung KH, Chien KH, Chen SY, Chen SN and Chen YT: Corneal neovascularization and contemporary antiangiogenic therapeutics. J Chin Med Assoc 78: 323-330, 2015.

8. Kenyon KR and Tseng SC: Limbal autograft transplantation for ocular surface disorders. Ophthalmology 96: 709-722; discussion 722-723, 1989.

9. Kolli S, Ahmad S, Mudhar HS, Meeny A, Lako M and Figueiredo FC: Successful application of ex vivo expanded human autologous oral mucosal epithelium for the treatment of total bilateral limbal stem cell deficiency. Stem Cells 32: 2135-2146, 2014.

10. Lee JY, Jeong HJ, Kim MK and Wee WR: Bone marrow-derived mesenchymal stem cells affect immunologic profiling of interleukin-17-secreting cells in a chemical burn mouse model. Korean J Ophthalmol 28: 246-256, 2014.

11. Kwitko S, Marinho D, Barcaro S, Bocaccio F, Rymer S, Fernandes $S$ and Neumann J: Allograft conjunctival transplantation for bilateral ocular surface disorders. Ophthalmology 102: 1020-1025, 1995.

12. Chan AA, Hertsenberg AJ, Funderburgh ML, Mann MM, Du Y, Davoli KA, Mich-Basso JD, Yang L and Funderburgh JL: Differentiation of human embryonic stem cells into cells with corneal keratocyte phenotype. PLoS One 8: e56831, 2013.

13. Arnalich-Montiel F, Pastor S, Blazquez-Martinez A, Fernandez-Delgado J, Nistal M, Alio JL and De Miguel MP: Adipose-derived stem cells are a source for cell therapy of the corneal stroma. Stem Cells 26: 570-579, 2008.

14. Cejkova J, Trosan P, Cejka C, Lencova A, Zajicova A, Javorkova E, Kubinova S, Sykova E and Holan V: Suppression of alkali-induced oxidative injury in the cornea by mesenchymal stem cells growing on nanofiber scaffolds and transferred onto the damaged corneal surface. Exp Eye Res 116: 312-323, 2013.

15. Gu S, Xing C, Han J, Tso MO and Hong J: Differentiation of rabbit bone marrow mesenchymal stem cells into corneal epithelial cells in vivo and ex vivo. Mol Vis 15: 99-107, 2009.

16. Jiang TS, Cai L, Ji WY, Hui YN, Wang YS, Hu D and Zhu J: Reconstruction of the corneal epithelium with induced marrow mesenchymal stem cells in rats. Mol Vis 16: 1304-1316, 2010.

17. Bianco P, Riminucci M, Gronthos S and Robey PG: Bone marrow stromal stem cells: Nature, biology, and potential applications. Stem Cells 19: 180-192, 2001.

18. Herzog EL, Chai L and Krause DS: Plasticity of marrow-derived stem cells. Blood 102: 3483-3493, 2003.

19. Tse WT, Pendleton JD, Beyer WM, Egalka MC and Guinan EC: Suppression of allogeneic T-cell proliferation by human marrow stromal cells: Implications in transplantation. Transplantation 75: 389-397, 2003.

20. Ribeiro A, Laranjeira P, Mendes S, Velada I, Leite C, Andrade P, Santos F, Henriques A, Grãos M, Cardoso CM, et al: Mesenchymal stem cells from umbilical cord matrix, adipose tissue and bone marrow exhibit different capability to suppress peripheral blood B, natural killer and T cells. Stem Cell Res Ther 4: 125, 2013. 
21. Ma Y, Xu Y, Xiao Z, Yang W, Zhang C, Song E, Du Y and Li L Reconstruction of chemically burned rat corneal surface by bone marrow-derived human mesenchymal stem cells. Stem Cells 24 315-321, 2006.

22. Guo T, Wang W, Zhang J, Chen X, Li BZ and Li LS: Experimental study on repairing damage of corneal surface by mesenchymal stem cells transplantation. Zhonghua Yan Ke Za Zhi 42: 246-250, 2006 (In Chinese).

23. Ye J, Yao K and Kim JC: Mesenchymal stem cell transplantation in a rabbit corneal alkali burn model: Engraftment and involvement in wound healing. Eye (Lond) 20: 482-490, 2006.

24. Liu XW and Zhao JL: Transplantation of autologous bone marrow mesenchymal stem cells for the treatment of corneal endothelium damages in rabbits. Zhonghua Yan Ke Za Zhi 43: 540-545, 2007 (In Chinese).

25. Oh JY, Kim MK, Shin MS, Lee HJ, Ko JH, Wee WR and Lee JH: The anti-inflammatory and anti-angiogenic role of mesenchymal stem cells in corneal wound healing following chemical injury. Stem Cells 26: 1047-1055, 2008.

26. Reinshagen H, Auw-Haedrich C, Sorg RV, Boehringer D, Eberwein P, Schwartzkopff J, Sundmacher R and Reinhard T: Corneal surface reconstruction using adult mesenchymal stem cells in experimental limbal stem cell deficiency in rabbits. Acta Ophthalmol 89: 741-748, 2011.

27. Liu H, Zhang J, Liu CY, Hayashi Y and Kao WW: Bone marrow mesenchymal stem cells can differentiate and assume corneal keratocyte phenotype. J Cell Mol Med 16: 1114-1124, 2012.

28. Yao L, Li ZR, Su WR, Li YP, Lin ML, Zhang WX, Liu Y, Wan Q and Liang D: Role of mesenchymal stem cells on cornea wound healing induced by acute alkali burn. PLoS One 7: e30842, 2012.

29. Pinarli FA, Okten G, Beden U, Fişgın T, Kefeli M, Kara N, Duru F and Tomak L: Keratinocyte growth factor-2 and autologous serum potentiate the regenerative effect of mesenchymal stem cells in cornea damage in rats. Int J Ophthalmol 7: 211-219, 2014.
30. Rohaina CM, Then KY, Ng AM, Wan Abdul Halim WH, Zahidin AZ, Saim A and Idrus RB: Reconstruction of limbal stem cell deficient corneal surface with induced human bone marrow mesenchymal stem cells on amniotic membrane. Transl Res 163: 200-210, 2014.

31. Du Y, Roh DS, Funderburgh ML, Mann MM, Marra KG, Rubin JP, Li X and Funderburgh JL: Adipose-derived stem cells differentiate to keratocytes in vitro. Mol Vis 16: 2680-2689, 2010.

32. Martinez-Conesa EM, Espel E, Reina $M$ and Casaroli-Marano RP: Characterization of ocular surface epithelial and progenitor cell markers in human adipose stromal cells derived from lipoaspirates. Invest Ophthalmol Vis Sci 53: 513-520, 2012.

33. Monteiro BG, Serafim RC, Melo GB, Silva MC, Lizier NF, Maranduba CM, Smith RL, Kerkis A, Cerruti H, Gomes JA and Kerkis I: Human immature dental pulp stem cells share key characteristic features with limbal stem cells. Cell Prolif 42: 587-594, 2009.

34. Nieto-Miguel T, Galindo S, Reinoso R, Corell A, Martino M, Pérez-Simón JA and Calonge M: In vitro simulation of corneal epithelium microenvironment induces a corneal epithelial-like cell phenotype from human adipose tissue mesenchymal stem cells. Curr Eye Res 38: 933-944, 2013.

35. Zeppieri M, Salvetat ML, Beltrami AP, Cesselli D, Bergamin N, Russo R, Cavaliere F, Varano GP, Alcalde I, Merayo J, et al: Human adipose-derived stem cells for the treatment of chemically burned rat cornea: Preliminary results. Curr Eye Res 38: 451-463, 2013.

36. Soleimani M and Nadri S: A protocol for isolation and culture of mesenchymal stem cells from mouse bone marrow. Nat Protoc 4: 102-106, 2009. 